Scand. Actuarial J. 1985: 49-63

\title{
The Pareto-optimal Design of Term Life Insurance Contracts
}

\author{
By David F. Babbel and Nicholas S. Economides
}

\section{Introduction}

Numerous investigations have been directed toward aspects of rational life insurance purchäses and optimal coverage levels under differing conditions. Most of these studies have taken as "given" the design of life insurance contracts and have focused on optimal consumer responses to available insurance opportunities. ${ }^{1}$ However, in works by Borch $(1960,1983)$, Arrow (1963, 1974) and Raviv (1979), contract design has been considered explicitly, yet in none of these studies has the focus been on life insurance; rather, general property and liability insurance received attention.

The present study focuses on the design of life insurance contracts. In it results are derived from first principles for the case of life insurance that have their analogues in the work of Arrow on general insurance. Aspects of the life insurance problem that diverge from other insurance problems lead to an optimal policy design that may differ from those appropriate for other lines of insurance. ${ }^{2}$ The simplicity of the lottery associated with life insurance allows us to describe consumers' coverage as a function of premium, facilitating a direct examination of alternative rate structures. This is in contrast to traditional approaches wherein optimality is described through relations of final wealth in different states of the world. We show, under very general conditions, how life insurance contracts can be designed so as to lead to increases in the welfare of insurance consumers, companies, and sales persons (i.e., insurance agents). Unlike other studies, which indicate that less than full coverage is optimal when a positive loading factor is incorporated into insurance rates, we show that full coverage is quite plausible under a positive loading factor, provided that the load is incorporated into insurance rates according to the manner herein specified. Another new result of this paper is that insurance consumers will desire higher

\footnotetext{
1 See, for example, Mayers \& Smith (1983). The studies have generally shown that term insurance is the optimal form of life insurance. Indeed Richard (1975) has claimed that all available forms of life insurance are linear combinations of one-period term insurance and a savings plan of some sort; accordingly, there is no loss of generality in focusing on term insurance, as will be done in this paper.

2 Subsequent to our first version of this paper (1981), Borch (1983) has reexamined the case of general insurance and shown that these contracts, when optimally designed, also share aspects of the Pareto optimal design presented here. Readers are referted to our earlier working paper for detailed proofs of the material contained herein.
} 
coverage levels, even though company profits and salesperson commissions are higher. Associated with this higher coverage is an equal or higher level of consumer welfare.

Both of these results stem from a restructuring of life insurance rate schedules and the imposition of a policy fee in accordance with the procedures outlined in this paper. Briefly, the magnitude of the policy fee would be set sufficiently high to include the salesperson's entire commission, the total expected profits associated with the policy, and a prorated portion of fixed company expenditures, while the marginal cost of coverage would correspond to the mortality probabilities.

The organization of this paper is as follows. First, a theoretical framework is introduced which will be used in examining the behavior of the major parties involved in life insurance policies. Next, consumer behavior is studied within this framework, followed by a discussion of firm behavior. A set of Pareto-optimal points is then derived which forms the contract curve, and it is shown that life insurance contracts without a policy fee accompanied by reduced marginal insurance costs are Pareto-inferior to those featuring such provisions. ${ }^{3}$ Next, the welfare of the insurance salesperson is considered and a sharing scheme is set forth by which all parties may derive increased welfare. The ultimate allocation of the welfare gain among all parties is, of course, subject to bargaining negotiations and market competition. ${ }^{4}$ In the final section, our results will be contrasted with those in other published studies on optimal insurance and contract design.

\section{The model}

The setting is a single-period two-state world in which there are three agents: a consumer, a firm, and an insurance salesperson. The consumer faces uncertainty in that his income varies beyond his control. This uncertainty arises from the unknown length of the consumer's life.

In state $S_{1}$ the consumer survives and earns income $H$ over and above his endowed wealth W $(Y=W+H)$. In state $S_{2}$ the consumer does not survive and has only $W$, his endowed wealth $(Y=W)$. It will be assumed that the objective possibilities of occurrence of these states are well defined and known but beyond the control or influence of all parties. Let $\pi$ denote the probability of the event $S=S_{2}$; then $1-\pi$ is the probability of the event $S=S_{1}$. The consumer is endowed with a concave expected utility function

\footnotetext{
3 There is one (theoretical) exception: if the insurer incurs no marketing or administrative costs but only the actuarial cost of insurance, then one of the Pareto-optimal points would have a zero policy fee.

There is a potential principal-agent problem in the distribution of the benefits between the insurance company and the salespersons. A fruitful analysis of this problem would involve an examination of alternatives to the firm, such as advertising, and the impact of these on the consumers. We will defer the treatment of this problem to a future paper.
} 
$U(\cdot)$ with $U^{\prime}(-\infty)=\infty$ and $U^{\prime}(\infty)=0$, assumed to be state dependent, and represented by function $V$ if $S=S_{1}$ and by function $B$ if $S=S_{2}$. The insurance firm offers coverage for the insured at an amount $I$ if he dies. In return the insured pays premium $P$ to the firm in both states of the world. ${ }^{s}$ The expected utility of the consumer when he has an insurance contract can be written in terms of the decision variables, $I$ and $P$, as:

$U(I, P)=(1-\pi) V(W+H-P)+\pi B(W+I-P)$

\section{Consumer behavior}

The consumer's problem is to maximize his expected utility choosing the pair $(I, P)$ that maximizes (1), given the contract $\mathrm{P}=f(I)$ offered by the firm. Making the usual assumptions about the utility function, i.e., that it increases with wealth, but at a diminishing rate, ${ }^{6}$ i.e., $V^{\prime}>0, V^{\prime \prime}<0, B^{\prime}>0$, and $B^{\prime \prime}<0$, it can be shown that the indifference curves $U(I, P)=$ constant $\vec{U}$ are concave, and the solution pair $\left(I^{*}, P^{*}\right)$ must satisfy

$\left.\frac{d I}{d P}\right|_{\text {contract }}=\left.\frac{d I}{d P}\right|_{U(I, P)=\dot{U}}$.

First order condition (2) characterizes the optimum provided that $U(I, P=f(I))$ is a quasiconcave function of $I$ and

$U\left(I^{*}, P^{*}\right)>U(0,0)$,

as entering into no contract remains an option of the consumer.

\section{Comparative Statics}

Having delineated the conditions that give rise to optimal coverage, we turn our attention to how the optimal level of insurance varies with changes in human wealth, $H$, nonhuman wealth, $W$, and insurance rate structure.

\footnotetext{
3 To avoid unnecessary complications that do not affect the major conclusions of this paper, the model employed in this presentation is timeless. A single-period, two-date model could be developed by redefining $\mathrm{H}$ and $\mathrm{l}$ as the present certainty-equivalent values of human wealth and the death benefit to be received at the end of the period, conditional upon obtaining the associated state of the world.

6 The partial derivatives of $U(I, P)$ are as follows:

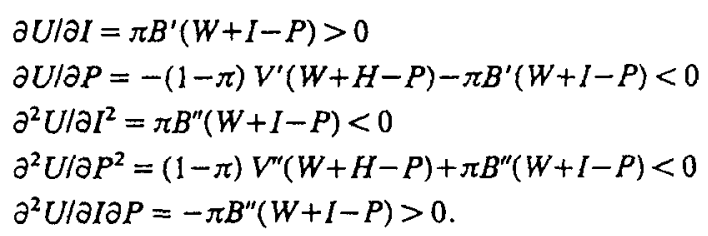


Consider the commonly offered linear contract ${ }^{7} \quad P=f(D)$ where $d P / d I=f^{\prime}(I)=1 / \mathrm{m}$. Observe that for all linear contracts the maximization problem is concave. ${ }^{8}$ Then (2) may be rewritten as

$m=1+\frac{1-\pi}{\pi} \cdot \frac{V^{\prime}(W+H-P)}{B^{\prime}(W+I-P)}$

which implies

$(m-1) \pi B^{\prime}(W+I-P)=(1-\pi) V^{\prime}(W+H-P)$
$(1-\pi) V^{\prime}(W+H-P)+(1-m) \pi B^{\prime}(W+I-P)=0$.

Observe that $m>1$. Let $f(W, H, P, I, m)=(1-\pi) V^{\prime}(W+H-P)+(1-m) \pi B^{\prime}$ $(W+I-P)$. Then $f\left(W, H, P^{*}, I^{*}, m\right)=0$ for all utility maximizing points $\left(l^{*}, P^{*}\right)$.

The manner in which optimal insurance coverage varies with human wealth is given by the sign of $d I^{*} / \mathrm{dH}$. $^{9}$

$$
\begin{aligned}
\frac{d I^{*}}{d H}=-\frac{\partial f / \partial H}{\partial f / \partial I^{*}} & =-\frac{(1-\pi) V^{\prime \prime}}{(1-\pi) V^{\prime \prime}\left(-\frac{1}{m}\right)+(1-m) \pi B^{\prime \prime}\left(1-\frac{1}{m}\right)} \\
& =\frac{m(1-\pi) V^{\prime \prime}}{(1-\pi) V^{\prime \prime}+(1-m)^{2} \pi B^{\prime \prime}}>0 .
\end{aligned}
$$

Thus, the optimal amount of insurance is increasing in the human wealth.

${ }^{7}$ Under the earlier stated assumption that the objective probabilities of the occurrence of states $S_{1}$ and $S_{2}$ are given from outside and known, well defined and beyond the influence of all parties, a linear contract is a reasonable form of a policy to offer. Indeed, when coupled with the assumption (made later) of risk-neutral insurers, it is an optimal form (Borch, 1983). The questions relating to Pareto-optimality concern its slope and intercept.

8 This is true provided that at $I=0$ the contract follows the positive $P$ axis. The slope of the contract is

$\left.\frac{d I}{d P}(0,0)\right|_{\text {concrest }}=0$

while the slope of the indifference curve through $(0,0)$ is

$\left.\frac{d l}{d P}(0,0)\right|_{U(I, P)=0}=\frac{(1-\pi) V^{\prime}(W+H)+\pi B^{\prime}(W)}{\pi B^{\prime}(W)}>0$.

Also we assume that the slope of the contract $d P / d I$ is bounded away from zero so that the optimum coverage is not infinite.

9 The following partial derivatives are used in the calculations:

$$
\begin{aligned}
& \partial f \partial W=(1-\pi) V^{\prime \prime}(\cdot)+(1-m) \pi B^{\prime \prime}(\cdot) \\
& \partial f l \partial H=(1-\pi) V^{\prime \prime}(\cdot)<0 \\
& \partial f f \partial I^{*}=(1-\pi) V^{\prime \prime}(\cdot)\left(-d P / d I^{*}\right)+(1-m) \pi B^{\prime \prime}(\cdot)\left(1-d P / d I^{*}\right)>0 \\
& \partial f l \partial m=(1-\pi) V^{\prime \prime}(\cdot)\left(-\frac{\partial P}{\partial m}\right)+(1-m) \pi B^{\prime \prime}(\cdot)\left(-\frac{\partial P}{\partial m}\right)-\pi B^{\prime}(\cdot)<0, \\
& \text { since }-\frac{\partial P}{\partial m}=\frac{1}{m^{2}}>0 .
\end{aligned}
$$

Scand. Actuarial J. 1985 
Insurance coverage will increase less than the full amount of a rise in human wealth if $d I^{*} / d H<1$, which will be the case if and only if ${ }^{10}$

$-\frac{V^{\prime \prime}(\cdot)}{V^{\prime}(\cdot)}<-\frac{B^{\prime \prime}(\cdot)}{B^{\prime}(\cdot)}$

Therefore, the optimal coverage increases with human wealth, but its increase is smaller than the increase in human wealth if (5) is true, which is interpreted as the absolute risk aversion at the "living" wealth (after coverage) being lower than the absolute risk aversion of the "bequest" wealth (after coverage).

Optimal insurance coverage will also vary with nonhuman wealth levels in accordance with the sign of $d I^{*} / d W$.

$$
\begin{aligned}
\frac{d I^{*}}{d W}=-\frac{\partial f l \partial W}{\partial f / \partial I^{*}} & =-\frac{(1-\pi) V^{\prime \prime}+(1-m) \pi B^{\prime \prime}}{(1-\pi) V^{\prime \prime}\left(-\frac{1}{m}\right)+(1-m) \pi B^{\prime \prime}\left(1-\frac{1}{m}\right)} \\
& =m \frac{(1-\pi) V^{\prime \prime}-(m-1) \pi B^{\prime \prime}}{\pi(m-1)^{2} B^{\prime \prime}+(1-\pi) V^{\prime \prime}} .
\end{aligned}
$$

The sign of the above derivative will be negative if and only if ${ }^{11}$

$-\frac{V^{\prime \prime}(\cdot)}{V^{\prime}(\cdot)}<-\frac{B^{\prime \prime}(\cdot)}{B^{\prime}(\cdot)}$

Therefore, the optimal coverage decreases in nonhuman wealth if (5) holds.

Finally we examine how optimal insurance varies with changes in the rate structure. From the partial derivatives given earlier, we know

$\frac{d I^{*}}{d m}=-\frac{\partial f l \partial m}{\partial f / \partial I^{*}}>0$

10 The derivation is as follows:

$$
\begin{aligned}
\frac{d I^{*}}{d H}<1 & \leftrightarrow \frac{m(1-\pi) V^{\prime \prime}}{(1-\pi) V^{\prime \prime}+(1-m)^{2} \pi B^{\prime \prime}}<1 \\
& \leftrightarrow m(1-\pi) V^{\prime \prime}>(1-\pi) V^{\prime \prime}+(1-m)^{2} \pi B^{\prime \prime} \\
& \leftrightarrow(m-1)(1-\pi) V^{\prime \prime}>(1-m)^{2} \pi B^{\prime \prime} \\
& \leftrightarrow(1-\pi) V^{\prime \prime}>(m-1) \pi B^{\prime \prime} \\
& \leftrightarrow(1-\pi) V^{\prime \prime}>\frac{1-\pi}{\pi} \pi B^{\prime \prime} \cdot \frac{V^{\prime}}{B^{\prime}} \\
& \leftrightarrow \frac{V^{\prime \prime}}{V^{\prime}}>\frac{B^{\prime \prime}}{B^{\prime}} \leftrightarrow-\frac{V^{\prime \prime}(\cdot)}{V^{\prime}(\cdot)}<-\frac{B^{\prime \prime}(\cdot)}{B^{\prime}(\cdot)}
\end{aligned}
$$

11 The derivation is as follows:

$$
\begin{aligned}
\frac{d I^{*}}{d W}<0 & \leftrightarrow[1-\pi] V^{\prime \prime}-(m-1) \pi B^{\prime \prime}>0 \\
& \leftrightarrow(1-\pi) V^{\prime \prime}>\frac{1-\pi}{\pi} \cdot \frac{V^{\prime}}{B^{\prime}} \cdot \pi B^{\prime \prime} \\
& \leftrightarrow \frac{V^{\prime \prime}}{V^{\prime}}>\frac{B^{\prime \prime}}{B^{\prime}} \leftrightarrow-\frac{V^{\prime \prime}(\cdot)}{V^{\prime}(\cdot)}<-\frac{B^{\prime \prime}(\cdot)}{B^{\prime}(\cdot)} .
\end{aligned}
$$




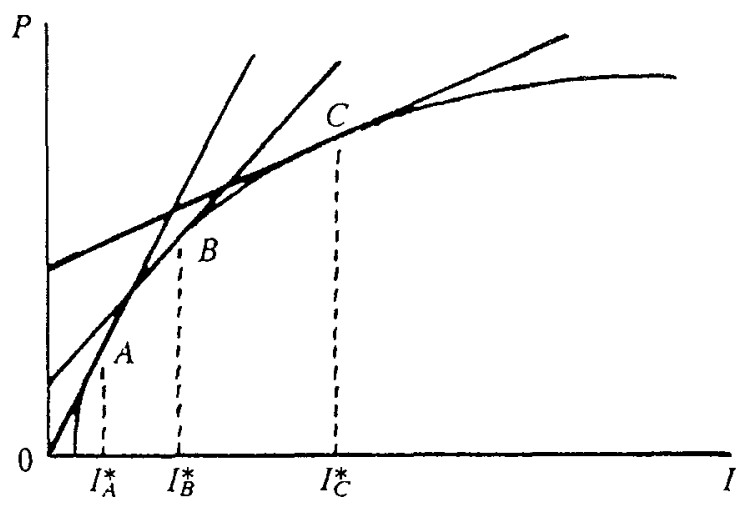

Fig. 1. Optimal coverage as a function of the rate structure.

We use this information to determine that

$\left.\frac{d I^{*}}{d\left(\frac{d P}{d I} \text { contr. }\right.}\right)=\frac{d I^{*}}{d\left(\frac{1}{m}\right)}=\frac{d I^{*}}{d m} \cdot \frac{d m}{d\left(\frac{1}{m}\right)}=\frac{d I^{*}}{d m} \cdot \frac{1}{\frac{d(1 / m)}{d m}}=-m^{2} \frac{d I^{*}}{d m}<0$.

This indicates that as the slope of the contract in the $(I, P)$ plane decreases, the optimal insurance coverage should increase, as shown below in Fig. 1. This finding is a direct consequence of the concavity of the indifference curves.

\section{Firm behavior}

We follow Rothschild \& Stiglitz (1976) in assuming that the firm's objetive is to maximize expected profits. This is a rather strong assumption which appears to be at variance with the theory of the firm, under which the maximization of firm values is heralded to be a more suitable objective. Only under certain conditions will maximization of expected profits lead to maximum firm value. Main (1981) and Goslings (1982) have shown that in the case of an insurance company (and more particularly in the case of a life insurance company) these conditions are approximately met. Total risk to the firm deriving from underwriting operations is very low and can be reduced substantially through operation of the Law of Large Numbers (see, for example, Sharpe (1978, pp. 82-84)). What little insurance risk remains is almost certainly "unsystematic" risk which should be irrelevant to the firm's shareholders in a perfect capital market. ${ }^{12}$ Accordingly, maximiza-

12 See, for example, Rubinstein (1973). This is not to say that life insurance companies do not exhibit systematic risk; rather, that the systematic risk is unlikely to derive from underwriting operations per se. Indeed, company profits may be affected by general economic conditions. In particular, as wages go up consumers may demand greater overage that could lead to higher 
tion of expected profits converges toward the maximization of the value of the firm.

Expected profits associated with contract of a coverage $I$ and premium $P$ are

$M(I, P, C)=-C-\pi I+P(1-\lambda)$.

The marketing agent (salesperson) is paid $\lambda P$ (as is the customary practice), $C$ is a fixed administrative cost associated with each policy, and $\pi I$ is the actuarial cost. The iso-profit curves are

$P=(\alpha+C+\pi I) /(1-\lambda)$,

i.e., straight lines with slope $\pi /(1-\lambda)$ and varying intercept. Expected profits are given by $\alpha$ :

$M(I, P, C)=-C-\pi I+P(1-\lambda)=\alpha$.

\section{Pareto-optimal contracts}

We will find Pareto-optimal points ${ }^{13}$ by letting the firm maximize its expected profits, $M$, subject to the condition that the consumer remains on the same indifference curve. Later, by changing parametrically the curve we will trace the entire Pareto-optimal frontier.

Given that the indifference curves for the consumer are concave in the $(I, P)$ plane and that the iso-profit curves for the firm are straight lines, the Pareto-optimal points will be specified by the tangency between an isoprofit curve and an indifference curve as shown in Fig. 2 below. Such a tangency condition is specified by the condition:

$$
\begin{aligned}
\left.\frac{d I}{d P}\right|_{U(I, P)=\hat{U}} & =\left.\frac{d I}{d P}\right|_{M(I, P)=\dot{M}} \\
& \leftrightarrow B^{\prime}(W+I-P) \cdot(1-\lambda-\pi)=V^{\prime}(W+H-P) \cdot(1-\pi)
\end{aligned}
$$

where $P$ is defined by (7). Equation (9) specifies a Pareto-optimal point,

profits. A more important source of systematic risk for life insurance companies is likely to derive from mismatching the "duration" of the firm's assets with that of its liabilities (see Grove (1974)). However, these considerations are properly separated from the underwriting problem and do not concern us here.

It should be noted that the unsystematic risk remaining may be relevant to the consumer, who might discount the promised benefit payment for its default risk. We assume here that the issued capital and retained earnings are sufficient to cover any "blips" in the claims distribution such that the promised death benefit can be regarded with certainty. Alternatively, reinsurance or a large insurance mutual fund could accomplish essentially the same result.

13 Pareto-optimal points are such that no agent can be made better off without hurting another agent. We ignore for the moment the third agent (salesperson) to facilitate the discussion. The third agent to the problem is discussed in Section VII. 


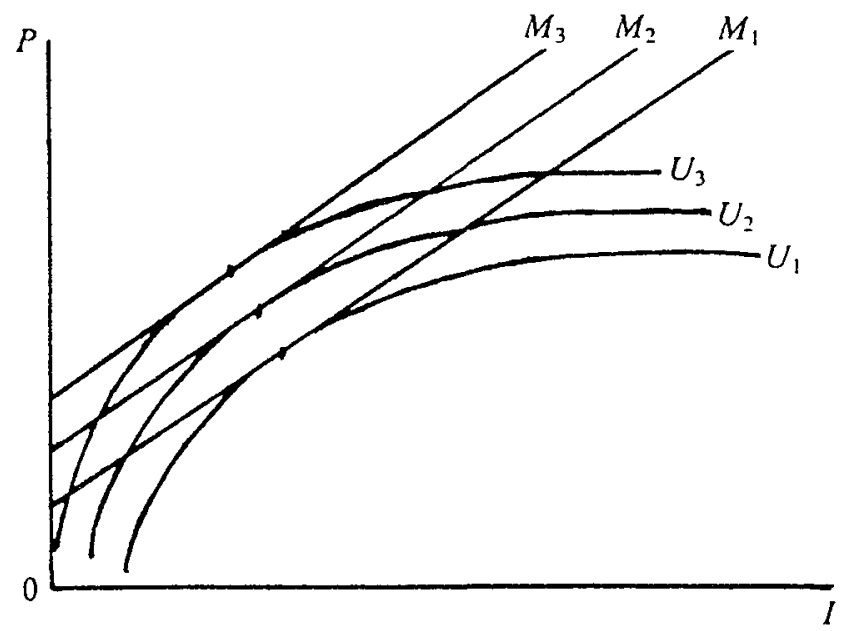

Fig. 2. Pareto-optimal points.

$(I, P)$. Varying the amount of profit $\bar{M}$, say through $a$, the entire locus of Pareto-optimal points, i.e., the Pareto-optimal frontier, can be traced. We now present some examples of Pareto-optimal contracts under special cases.

Special Case 1: No marketing costs

Say $\lambda=0$, i.e., that there is no marketing cost (insurance agent fee). Then the Pareto-optimal contract is

$P=\alpha+C+\pi I$

Condition (9) still holds, with $P$ defined by (10). Condition (9) implies that $B^{\prime}(W+I-P)=V^{\prime}(W+H-P)$, that is, at the Pareto-optimal point, insurance is purchased up to an amount that equalizes the marginal utility of wealth in states $S_{1}$ and $S_{2}$.

If $B^{\prime}=V^{\prime}$, i.e., if the bequest utility function $B$ is a translation of the "living" utility function $V$, then in this case $I^{*}=H$. The consumer will buy full coverage. Note that the above results do not depend on the amount of profits that the company makes, as long as the consumer is not pushed to an indifference curve of lower utility than the indifference curve of no coverage.

Special Case 2: Zero expected firm profits

Assume that the firm expects zero profits (say because of intense competition among firms). Then $M=\alpha=0$. The Pareto-optimal contract is

$P=[C+\pi \Gamma] /(1-\lambda)$

Condition (9) still holds with $P$ defined by (11).

Special Case 3: No fixed costs

Assume that $C=0$, i.e., that there are no fixed costs per contract. Then the Pareto-optimal contract is 


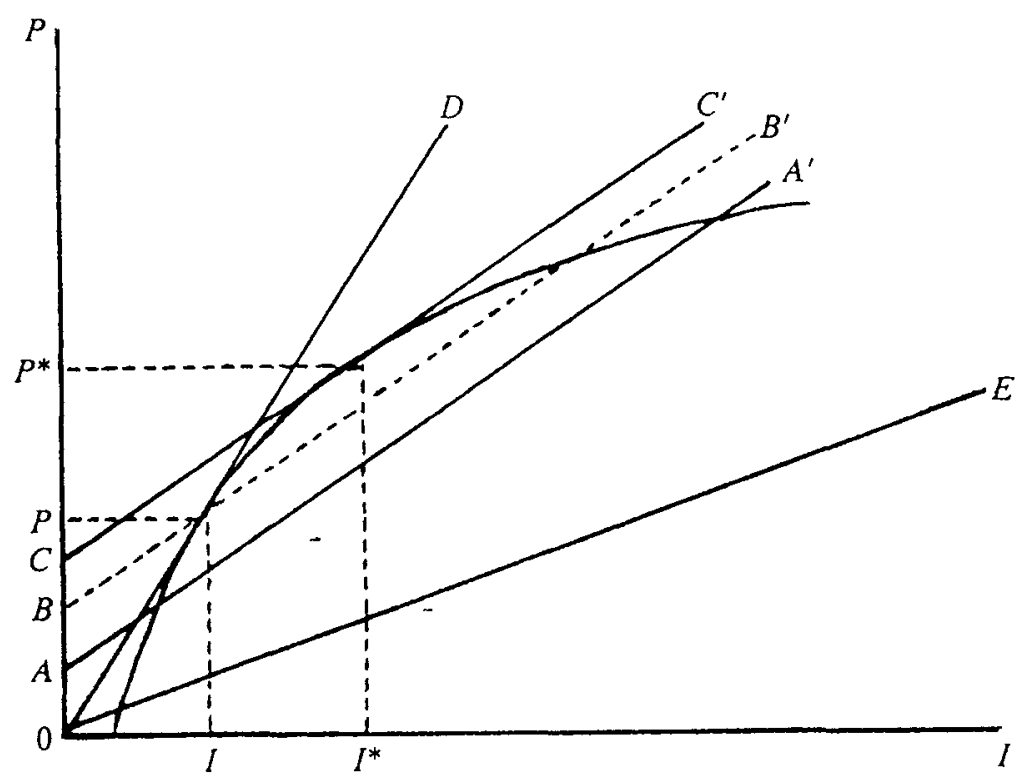

Fig. 3. Suboptimality of contracts without policy fee accompanied by lowered marginal cost of insurance coverage.

$P=[\alpha+\pi I /(1-\lambda)$

Condition (9) still holds, with $P$ defined by (12).

\section{Suboptimality of contracts with no policy fee}

Suppose the contract

$P=\mu I$

is offered. Such a contract results in a Pareto-inferior position. It is dominated by a contract of the form

$P=[\alpha+C+\pi n] /(1-\lambda)$

that results in a Pareto-optimal position.

To see this, assume that the consumer and firm are at a position $\left(I^{*}, P^{*}\right)$ where (7) and (9) hold. Then by the proof of Pareto optimality it follows that (13) gives less to one of these parties. If the consumer is held at the same indifference curve $U(I, P)=U\left(I^{*}, P^{*}\right)$, then the firm loses money by moving to the new contract, as shown in Fig. 3 below.

In Fig. 3, $O E$ gives the actuarially fair cost of insurance $\pi I$, for all levels of coverage, $I$. $A A^{\prime}$ depicts the iso-profit line of zero expected firm profits, where $C=(1-\lambda) \overline{O A}$ and the salesperson's commission rate $\lambda$ is implicit in the slope of the line, which is steeper than $O E$. The Pareto-optimal point $\left(I^{*}, P^{*}\right)$ is attained where the indifference curve is tangent to $C C^{\prime}$, which is the contract given by (7) where the expected profit is $\alpha=(1-\lambda) \overline{A C}$. The 
alternative contract given by (13) is represented by $O D$. Note that the expected profit associated with this contract is given by $(1-\lambda)$ of the vertical distance between the zero iso-profit line $A A^{\prime}$ and the (parallel) isoprofit line $B B^{\prime}$ passing through the new tangency point of the indifference curve with the contract line (13). Clearly the expected profit deriving from this alternative contract, $(1-\lambda) \overline{A B}$ is less than that expected from the Pareto-optimal contract, $(1-\lambda) \overline{A C}$ and yet the consumer is no better off.

This is a direct result of the concavity of the indifference curve for the consumer contrasted with the linearity of the iso-profit curves of the firm. In some sense the whole society loses by moving from contract (7) to contract (13). The risk averse consumer is not adequately covered, given the features of the risk neutral insurer. A risk neutral insurer can make profit by offering a contract that would move the consumer from position $(I, P)$ to position $\left(I^{*}, P^{*}\right)$.

Another finding of note is that in addition to the firm receiving higher profits under a Pareto-optimal contract of form (7) while holding the insurance consumer's utility level constant, the insurance sales agent, whose total commission is $\lambda P$ under the typically offered contract (of form (13)) receives a windfall gain from the Pareto-optimal contract design (of form (7)), which provides a commission $\lambda P^{*}>\lambda P$. As there is no reason why the salesperson should necessarily reap all of this welfare gain, we next examine the sharing rules among between the firm and the sales agent. ${ }^{14}$

\section{Sharing rules}

Up to this point we have assumed that the salesperson is paid a proportional amount of the premium. Now we investigate different contractual arrangements between the agent and the firm which will allow for mutual benefits without reducing the welfare of consumers.

Assume that from the total premium the firm keeps $G(P, \lambda)$ and the salesperson receives the remainder, $P-G(P, \lambda)$. Let $M=-\pi I+G(P, \lambda)-C$ denote the profit received by the firm and $A=-J+P-G(P, \lambda)$ denote the net commission received by the salesperson, where $J$ is a measure of the salesperson's "effort" expended to obtain the sale. ${ }^{15}$ Together these sum

\footnotetext{
14 Up to this point we have held the consumer's utility constant while increasing the expected profits of the firm (and commissions of the salesperson). Of course, there is no particular reason why the insurer (and salesperson) should capture all the gain arising from Paretooptimally designed life insurance contracts. Indeed, at the other extreme, sales commissions and profitability could have been held constant while the consumer reaped all of the gain deriving from the new contract design. More likely, the ultimate allocation of the gain will be determined by bargaining among the agents, with each of the three agents capturing a portion of the gain.

15 In a model such as ours, where the insurance consumer is assumed to make decisions on a rational basis, tha amount of sales is not modeled as a function of the level of persuasive effort put forth by the sales agent; rather, the sales agent's effort consists simply in presenting the necessary policy information to the consumer, who then makes the decision.
}

Scand. Actuarial J. 1985 
to $A+M=-\pi I+P-J-C$. At a Pareto-optimal point.

$\frac{d A}{d \lambda}=-\frac{d M}{d \lambda} \leftrightarrow \frac{d(A+M)}{d \lambda}=0 \leftrightarrow \frac{d P}{d \lambda}\left(1-\pi \frac{d I}{d P}\right)=0$

It is sufficient to have $d P / d l=\pi$. Then, $P=\alpha^{\prime}+C+\pi I$ is the form of a Paretooptimal contract offered by the firm.

In the arrangement where $G(P, \lambda)=(1-\lambda) P$, this corresponds to $\lambda=0$. It will give $A=-J$ to the insurance salesperson and is therefore unacceptable.

A Pareto-optimal arrangement will give a "lump sum" " $X$ " to the salesperson per contract: $P=\alpha+C+\pi I+X$. Now $A=-J+X$. Clearly $X$ must not be smaller than $J$. The amount $X$ is an item of bargaining between the sales agent and the firm. The amount should be at least as large as $\lambda P$ (of the $P$ indicated in Fig. 3) for the salesperson to be as well off as he was with the Pareto-inferior contract.

An important observation is that under a Pareto-optimal contract of form $P=a^{\prime}+C+\pi I$, where firm profitability and sales commissions are embedded in the $\alpha^{\prime}$ component of the "policy fee" (of magnitude $\alpha^{\prime}+C$ ), full insurance coverage will be purchased by an expected utility maximizing consumer, provided that (1) $B^{\prime}=V^{\prime}$ (i.e., the bequest utility function $B$ is a translation of the "living" utility function $V$ ) and (2) the consumer is not pushed to an indifference cirve of lower utility than the indifference curve of zero coverage (see special case 1 , Section V).

\section{Concluding remarks}

The problem of insurance has attracted considerable attention in the economic literature over the past thirty years, and it is surprising that the Pareto-optimal design of life insurance contracts has received so little attention. Perhaps a reason for this is that life insurance is typically examined in state space rather than the $(I, P)$ space employed here, where policy rate structures are observed directly. The same results can be achieved in state space analysis, however. Rather than replicate all of our results in state space, we will here only provide a diagrammatic overview of the problem. The initial part of the exposition follows closely that given by Klein (1975).

In Fig. 4 the endowed wealth position of the consumer in state space is given by point $A$, where $W+H$ measures consumption claims if state $S_{2}$ is revealed. The $45^{\circ}$ line is termed the certainty line. (If a family holds claims somewhere along this line, their consumption status would be unaffected by the breadwinner's mortality status.) Typically $H>0$ so that the initial endowment point $\mathrm{A}$ lies beneath the $45^{\circ}$ line.

Indifference curve 1 is simply the locus of wealth level combinations across states that yield the same level of expected utility as the endowment point A. Diminishing marginal utility is sufficient to insure strict convexity 


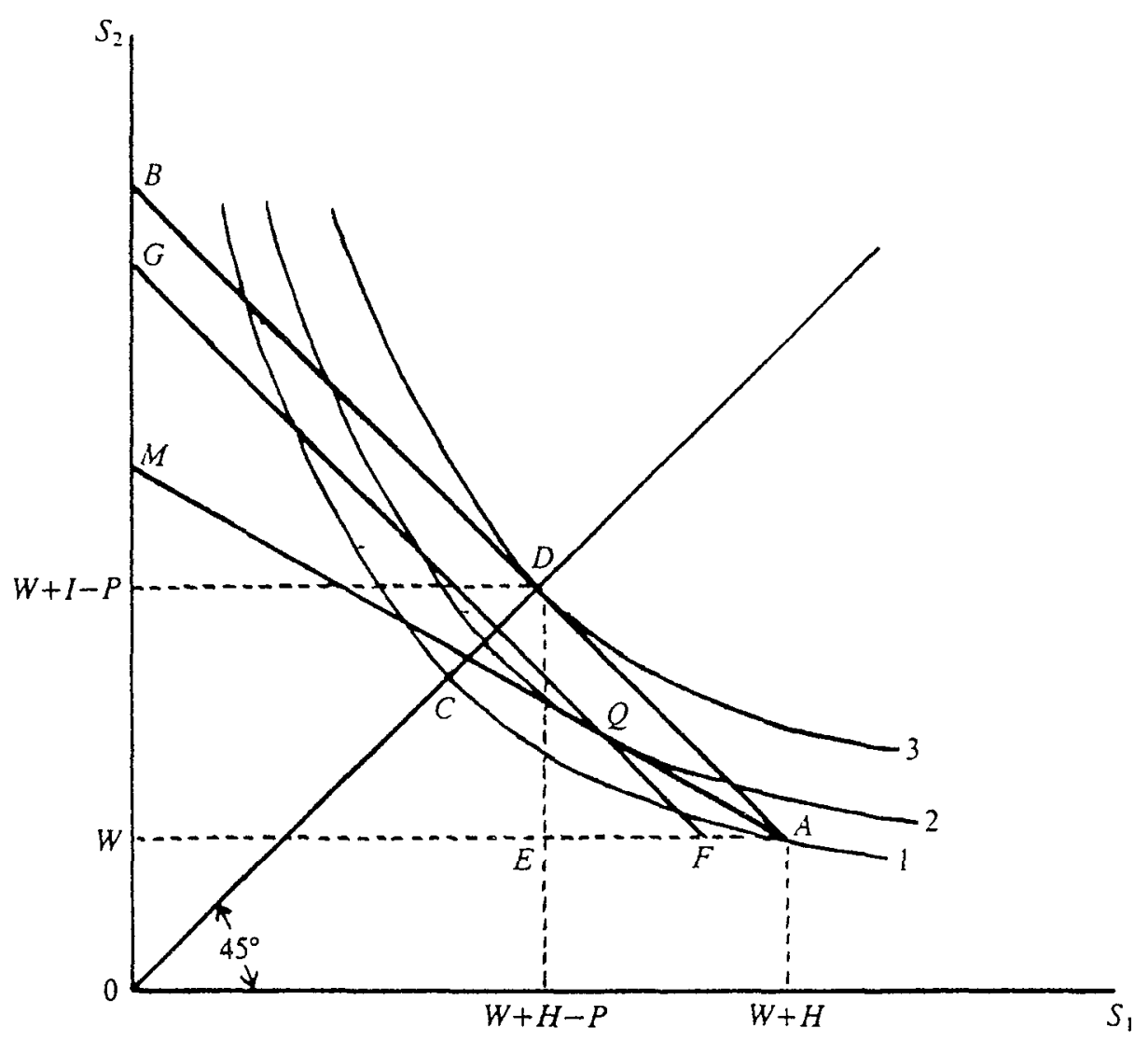

Fig. 4. Insurance in state space.

of the indifference curves. Beginning at point $A$ is the line segment $A B$, which represents the family's opportunity set, assuming that it can purchase life insurance at a price equal to the reciprocal of the negative of the slope of $\overline{A B}$. Suppose that consumption claims in one state can be traded for consumption claims in the other state at a prices $(1-\pi) / \pi$. The slope of $A B$ is $-[(1-\pi) / \pi]$. Under these conditions, the purchase of insurance would amount to the acceptance of an actuarially fair bet, i.e., one whose expected return is zero. It is well known that the optimum for an individual with a unique utility function $(B(\cdot) \equiv V(\cdot))$ would then be along the certainty line and the pictured consumer would move to point $D$ and achieve a level of expected utility denoted by the higher indifference curve 3 . He would give up $A E=P$ units of income in state $S_{1}$ for $E D=I-P$ units of income in state $S_{2}$.

If the insurance were actuarially unfair in the usual sense (where the slope of the contract is altered), then a flatter contract such as $A M$ would be offered. Then the consumer's choice would not be on the certainty line, but below it, at $Q$, on indifference curve 2. Such a contract would not be Pareto optimal, however. A Pareto optimal contract is represented in this diagram by a horizontal line segment moving leftward from point $A$, for example 
$A F$, to account for the policy fee (which will be divided among fixed administrative costs, sales commissions, and profits) and a rising line segment, such as $F G$, parallel to the actuarially fair contract line $A B$. In the case of a unique utility function as shown here, full insurance would be purchased for any parallel contract cutting the $45^{\circ}$ line at a point between $C$ and $D$.

In summary, we have shown that under present arrangements, where insurance agents are generally paid commissions based upon the size of the insurance premium, both the insurer and insured can be made better off if the marginal cost of insurance is reduced so as to include only the actuarially fair cost plus the sales agent commission, while imposing a policy fee of appropriate size to cover fixed costs and company profits. The sales agents would also benefit under this system because consumers are likely to seek higher levels of coverage and pay larger premiums, thereby leading to higher sales commissions.

It is possible to achieve still greater welfare gains. This would entail further restructuring of policy terms so that a larger policy fee is charged and the marginal cost of insurance is reduced further to correspond only to its actuarially fair cost. Such a policy design should generate a larger welfare gain to be distributed among the three parties, one that allows each party to be better off than under the current arrangement or first proposal. The policy fees that such contracts would entail should not be confused with the token policy fees that are currently charged by some insurers. Rather, the magnitudes would need to be sufficient to provide for all of the sales commission, a prorated portion of fixed company costs, and the total expected profit associated with the policy. ${ }^{16}$

We conclude by comparing the optimal life insurance contract design with that for other insurance lines. Arrow $(1963,1974)$ has shown that, for risk neutral insurers, a Pareto-optimal insurance contract for a general loss distribution is a linear, full coverage contract above a deductible minimum. ${ }^{17}$ The full coverage is optimal even when the premium is characterized by proportional loading, and the deductible is paid by the insured only in the states where losses occur. There is no policy fee, and the problem of sales agents is not considered. Raviv (1979) has investigated the necessary and sufficient condition for the Pareto-optimal contract to include a nontrivial deductible and to involve coinsurance.

\footnotetext{
16 The reader should be reminded that only the case of a single representative consumer was analyzed.

17 Borch (1983) has pointed out that "Deductibles do not seem very relevant in a theory of risk bearing, which assumes that insurers are risk neutral ... If the insurer is risk neutral, i.e., if he is interested only in expected profits, there must exist a premium (above the actuarially fair value) which will induce a risk averse buyer to take full insurance cover. Deductibles should be seen as a practical device for avoiding the expenses involved in checking and paying compensation for negligible losses".
} 
While we also propose a linear contract for life insurance, our design features a sizeable policy fee paid independently of whether a loss of life occurs, but no deductible paid in the event of death. Moreover, we show that full coverage is generally not optimal under a proportional premium loading scheme, ${ }^{18}$ but may be optimal under an additive loading scheme. Our proposal of an actuarially fair rate structure at the margin also involves altering the compensation schedule for insurance sales agents. Further, the expected profits for the insurer are no longer a direct function of the size of the policy sold.

These differences in optimal contract design derive from differences in the insurer cost function. The problem of moral hazard, while important in other lines of insurance, is small in life insurance, as it involves a tremendous cost to the insured-his or her life. In other lines of insurance, large costs are incurred in monitoring and assessing the size of losses, as indemnification is usually a prespecified proportion of the future loss (above a deductible), a random variable that ranges from zero to partial to full loss. In the case of life insurance, estimating the value of human capital lost in the event of death is of no consequence to the insurer, who has a fixed dollar contingency, although it is of concern to the insured and beneficiary. ${ }^{19}$ These differences have led to the dissimilarities in optimal policy design.

Earlier versions of this paper appeared as IBER Working Paper No. 115, University of California, Berkeley, and Department of Economics Discussion Paper No. 155, Columbia University.

\section{Acknowledgements}

This research was supported by grants from the Institute of Business and Economic Research and from the Berkeley Program in Finance. The authors are indebted to Karl Borch, Nils Hakansson, Andreu Mas-Colell, Hayne Leland, Mark Rubinstein, Yuk-Shee Chan and Jean Paul Cresta and an anonymous referee.

\section{References}

Arrow, K. J. (1963). Uncertainty and the welfare economics of medical care. American Economic Review 53, 941-973.

Arrow, K. J. (1974). Optimal insurance and generalized deductibles. Scandinavian Actuarial Journal, $1-42$.

Borch, K. (1960). The safety loading of reinsurance premiums. Skandinavisk Aktuarietidskrift, 163-184.

Borch, K. (1962). Equilibrium in a reinsurance market. Econometrica 30, 424-444.

\footnotetext{
18 Borch (1962) discusses the circumstances under which the proportional loading factor may be dictated in the case of general insurance. In our model, where the insured is characterized as having state-dependent utility functions, one could envisage configurations of utility shapes that would justify full coverage even under a proportional loading factor.

19 In practice, and in the case of very large policies, some expense may be incurred to verify that death was accidental, so that contractual stipulations are met.
} 
Borch, K. (1983). The optimal insurance contract in a competitive market. Economic Letters 11, 327-330.

Economides, N. (1982). The demand for life insurance: An application of the economics of uncertainty: Comments. Journal of Finance, 1305-1309.

Goslings, J. H. W. (1982). Risk structure and reinsurance. Centraal Beheer, Apeldoorn, The Netherlands.

Grove, M. A. (1974). On duration and the optimal maturity structure of the balance sheet. Bell Journal of Economics and Management Science 5, 696-709.

Klein, M. A. (1975). Optımal life insurance: Comment. Journal of Finance 30, 904-908.

Main, B. G. M. (1981). The firm's insurance decision. Some questions raised by the capital asset pricing model. Managerial and Decision Economics 1 (December).

Mayers, D. \& Smith, C. (1983). The interdependence of individual portfolio decisions and the demand for insurance. Journal of Political Economic 91, 304-311.

Raviv, A. (1979). The design of an optimal insurance policy. American Economic Review 69, 84-96.

Richard, S. F. (1975). Optimal consumption, portfolio and life insurance rules for an uncertain lived individual in continuous time model. Journal of Financial Economics 2, 187-203.

Rothschild, M. \& Stiglitz, J. (1976). Equilibrium in competitive insurance markets: An essay on the economics of imperfect information. Quarterly Journal of Economics 90, 629-650.

Rubinstein, M. E. (1973). A mean variance synthesis of corporate financial theory. Journal of Finance 28, 167-181.

Sharpe, W. (1978). Investments. '1st ed. Prentice-Hall, Englewood Cliffs.

Stuart, C. (1983). Pareto-optimal deductibles in property-liability insurance: The case of homeowner insurance in Sweden. Scandinavian Actuarial Journal, 227-238.

Received October 1984

David F. Babbel

Graduate School of Business Administration

University of California at Berkeley

Berkeley, California U.S.A. 94720

Nicholas S. Economides

Department of Economics

Columbia University

New York City, New York U.S.A. 10027 